\title{
A leitura e a escrita de textos paradidáticos na formação do futuro professor de Física
}

\author{
Reading and writing paradidact textbooks texts \\ in the training of future teachers of Physics
}

Micaías Andrade Rodrigues ${ }^{1}$

\begin{abstract}
Resumo: Este artigo remete à importância do uso de textos paradidáticos na formação dos licenciandos em Física, com base na experiência ocorrida na Universidade Federal do Piauí, onde trabalhamos em uma turma de 23 de Metodologia do Ensino de Física em dois momentos. No primeiro momento, houve leitura e discussão de textos paradidáticos de Física e, no segundo momento, escrita (continuação) de uma estória já iniciada, inserindo nesta conceitos de Física. Estas atividades mostraram-se extremamente positivas e desafiadoras, especialmente na escrita, visto que os alunos não apresentaram um domínio nem da escrita formal nem dos conceitos de Física, que foram apresentados, algumas vezes, erroneamente. Como resultado, percebemos que os alunos acharam interessante a utilização e produção destes textos, pois, além de terem baixo custo e ampliarem as possibilidades metodológicas no ambiente escolar, abordam conceitos da Física no cotidiano, diminuindo a distância entre a Física lecionada na escola e a realidade dos alunos.
\end{abstract}

Palavras-chave: Ensino de Física. Formação de professores. Textos paradidáticos. Leitura. Escrita.

\begin{abstract}
This paper refers to the importance of using of paradidactic texts in the training of undergraduates in physics, based on experience occurred on the UFPI, where we work in a class of 23 students in Physics Teaching Methodology in two phases: reading and discussion of texts Physics textbooks (first); writing (continuation) a story already begun by inserting concepts of physics (second). These activities were extremely positive and challenging, especially the writing, since the students did not have experience of such writing nor the formal concepts of physics, which were presented, sometimes erroneously. As a result, we realized that the students found the use and production of these texts interesting, because in addition to being a low cost and able to extend the methodological possibilities in the school environment, addressing concepts of physics in everyday life, they narrowed the gap between the physics taught in school and the reality of the students.
\end{abstract}

Keywords: Physics teaching. Teacher education. Paradidactic texts. Reading. Writing.

\footnotetext{
${ }^{1}$ Departamento de Métodos e Técnicas de Ensino, Centro de Ciências da Educação, Universidade Federal do Piauí (UFPI), Campus Petrônio Portella, Ininga, CEP 64049-550, Teresina, PI, Brasil.

E-mail: <micaias@ufpi.edu.br>
} 


\title{
Introdução
}

A Lei 9.394 (BRASIL, 1996, p. 15) - a Lei de Diretrizes e Bases da Educação Nacional (LDB) - afirma, no seu artigo 36, entre outras coisas, que o currículo do Ensino Médio:

\begin{abstract}
I - destacará a educação tecnológica básica, a compreensão do significado da ciência, das letras e das artes; o processo histórico de transformação da sociedade e da cultura; a língua portuguesa como instrumento de comunicação, acesso ao conhecimento e exercício da cidadania;

II - adotará metodologias de ensino e de avaliação que estimulem a iniciativa dos estudantes; [...]
\end{abstract}

Afirma ainda, neste mesmo artigo, que os conteúdos, as metodologias e as formas de avaliação serão organizados de forma que, ao final do Ensino Médio, o educando demonstre, entre outros, o domínio dos princípios científicos e tecnológicos que presidem a produção moderna e conhecimento das formas atuais de linguagem.

As bases legais dos Parâmetros Curriculares Nacionais (BRASIL, 2000) comentam que a organização curricular do Ensino Médio deve ser orientada para reconhecer as linguagens como formas de constituição dos conhecimentos e das identidades, portanto, como o elemento-chave para constituir os significados, conceitos, relações, condutas e valores que a escola deseja transmitir. Esta linguagem pode ser a de algoritmos na matemática e Física, a escrita, a verbal ou, ainda, a não verbal, por meio dos gestos e atitudes.

Em relação ao uso das diferentes linguagens no ensino das Ciências Naturais, as Orientações Complementares aos Parâmetros Curriculares Nacionais (PCN+) (BRASIL, 2002, p. 24) afirmam que

O domínio de linguagens, para a representação e a comunicação científico-tecnológicas, é um campo comum a toda a ciência e a toda a tecnologia, com sua nomenclatura, seus símbolos e códigos, suas designações de grandezas e unidades, boa parte dos quais já incorporada à linguagem cotidiana moderna. A articulação dessa nomenclatura, desses códigos e símbolos em sentenças, diagramas, gráficos, esquemas e equações, a leitura e interpretação destas linguagens, seu uso em análises e sistematizações de sentido prático ou cultural, são construções características dessa área de conhecimento, mas hoje integram um instrumental igualmente necessário para atividades econômicas e para o pensamento social.

O documento citado para ressaltar a importância dos códigos e linguagens no estudo das Ciências da Natureza e Matemática criou, como um dos objetivos educacionais no Ensino Médio, a Representação e comunicaşão ${ }^{2}$, e comenta que o desenvolvimento de códigos e linguagens

\footnotetext{
${ }^{2}$ Os outros objetivos listados são: a investigação e compreensão, e contextualização sociocultural.
} 
em ciência e tecnologia deve ser tomado como um aspecto formativo de cada disciplina científica.

Dentro desta perspectiva, os PCN + Ciências da Natureza, Matemática e suas Tecnologias (BRASIL, 2002) continuam afirmando que já se percebem experiências importantes em muitas escolas brasileiras que desenvolvem novos projetos pedagógicos e novas práticas educacionais, nas quais leituras, investigações, discussões e projetos realizados por alunos superam ou complementam a didática da transmissão e a pedagogia do discurso. Essas novas práticas, usualmente, são resultado de um trabalho de toda a comunidade, em cooperação com a direção escolar, em apoio à transição entre o velho e o novo modelo de escola.

Os PCN+ (BRASIL, 2002) comentam que tanto o sentido cultural do aprendizado quanto o sentido prático podem ganhar muito em profundidade ou amplitude através da leitura e da elaboração de manuais de instrução, ou de outros textos técnicos, que se viabilizam e se completam pelo uso das linguagens textuais, gráficas e pictóricas combinadas. A Matriz Curricular do Exame Nacional do Ensino Médio (BRASIL, 2009), ao tratar sobre a competência Entender métodos e procedimentos próprios das ciências naturais e aplicá-los em diferentes contextos, na Matriz de Referência de Ciências da Natureza e suas Tecnologias, cita a seguinte habilidade: "Relacionar informações apresentadas em diferentes formas de linguagem e representação usadas nas ciências Físicas, químicas ou biológicas, como texto discursivo, gráficos, tabelas, relações matemáticas ou linguagem simbólica” (BRASIL, 2009, p. 9).

Desta forma, a maneira habitual com que os alunos de Física entram em contato com a disciplina, com imensas listas de exercícios, memorização de fórmulas e descontextualizada da realidade dos alunos (ANDRADE; MAIA JR., 2008; BEZERRA et al., 2009; CAVALCANTE et al., 2009; MONTEIRO; TEIXEIRA, 2004; REIS; LINHARES, 2008; TEIXEIRA, 2003) mostra-se em direção contrária ao que rege a lei supracitada. Para modificar isto, os $\mathrm{PCN}+$ nos dão como sugestão utilizar os meios de informação contemporâneos que estiverem disponíveis na realidade do aluno, tais como: notícias de jornal, livros de ficção científica, literatura, programas de televisão, vídeos, promovendo diferentes leituras e/ou análises críticas; e enfatiza que uma prova pode ser, também, um momento de aprendizagem, especialmente em relação ao desenvolvimento das competências de leitura e interpretação de textos e enfrentamento de situações-problema.

Tendo em vista estas coisas, nos ocorreram as seguintes questões: seria possível trabalhar conceitos de Física por meio de breves textos paradidáticos? $?^{3} \mathrm{E}$ estes textos poderiam aproximar a Física da realidade dos alunos? Antes de tratamos sobre a metodologia da pesquisa, trataremos sobre a importância da leitura e da escrita na formação do sujeito.

\footnotetext{
${ }^{3}$ Textos paradidáticos são textos que complementam o material didático, que, normalmente, é o livro didático. Neste artigo, o que chamamos de textos paradidáticos são pequenos textos literários, que abordam conceitos de Física em situações do cotidiano.
} 


\section{A importância da leitura e da escrita na formação do sujeito}

Os textos paradidáticos podem ser utilizados como uma ferramenta didática capaz de viabilizar a compreensão do aluno relativa aos conceitos apresentados, bem como oferecer, ao estudante, a possibilidade de interagir reflexiva e criticamente com o seu meio social, desenvolvendo e vivenciando a sua cidadania.

Almeida e Sorpreso (2011) ressaltam que as leituras não produzem um único significado, e nos trazem, à reflexão, a conveniência do acesso a muitos tipos de discursos para um mesmo conteúdo, enfatizando que a prática da leitura de diferentes textos (artigos científicos, textos de divulgação científica, livros didáticos) parece uma perspectiva promissora para a educação. Os autores exemplificam que, um estudante que resista ao estudo por livros didáticos, pode gostar de ler textos de divulgação científica; e que o aprendizado decorrente da leitura dos diferentes tipos textuais, certamente, não será o mesmo, porém, nos dois casos, provavelmente ocorrerão crescimentos culturais significativos. Castelló, Bañales Faz e Vega López (2011) concordam com o pensamento dos autores supracitados e acrescentam que, ao lerem textos de diferentes formatos, os estudantes universitários que irão produzir um texto acadêmico novo devem integrar as informações destes diferentes textos, colocando-se em uma posição mista entre leitor e escritor. Para estes autores, para escrever um novo texto acadêmico, o aluno-escritor deve ter claros: o propósito do texto, o tema, os objetivos, a fundamentação teórica e o formato, levando em consideração a comunidade onde escreve e a que se dirige.

Almeida e Sorpreso (2011) também nos alertam para a possível hierarquia entre diferentes linguagens no ensino, a qual chamam de equívoco e citam como exemplo, no ensino da Física, quando é proposto que se ensine determinado conteúdo primeiro conceitualmente (linguagem comum) e, só depois, as operações (linguagem matemática). Como alternativa, esses autores sugerem que as duas modalidades caminhem paralelamente, e ressaltam não ser possível uma tradução total de uma linguagem na outra, mas, também, por não conhecer as histórias de cada estudante e as conexões que ocorrerão em suas memórias discursivas na produção de significados.

Esta visão também é compartilhada por Cassiani, Von Linsingen e Giraldi (2011), que identificam, em seu trabalho, algumas concepções de leitura diferenciadas e categorizam duas: a primeira voltada à questão da leitura de textos em si, em que a leitura torna-se importante por propiciar a apropriação de bens culturais por parte do leitor; e a segunda visão, a qual estes consideram mais abrangente, que aponta para a leitura como uma forma de entender o mundo.

Sobre a primeira concepção, Chartier (1996 apud ASSOLINI, 2011, p. 35) traz para a discussão a concepção de leitura enquanto prática cultural, que obedece às mesmas leis que outras práticas culturais, com a diferença de que ela é mais diretamente ensinada e propagada pelo sistema escolar. Sobre a segunda concepção Cassiani, Von Linsingen e Giraldi (2011) afirmam que esta perspectiva se aproxima muito do que Paulo Freire defende em suas teses, segundo as quais, a tomada da palavra relaciona-se com as formas de ver o mundo. A leitura, assim, vai muito além da leitura das palavras. É uma leitura de contextos, que promove uma visão mais crítica sobre o mundo que nos rodeia.

Freire (2004) afirma que a leitura do mundo precede a leitura das palavras e que o docente deve respeitar a "leitura do mundo" com que o educando chega à escola. Sobre isto, 
Cassiani, Von Linsingen e Giraldi (2011) afirmam que um texto é sempre incompleto, pois seus sentidos não derivam das palavras ou das expressões em si, mas são constituídos com base na intertextualidade e no interdiscurso, na sua relação com a exterioridade.

A utilização de textos paradidáticos em aulas de Física, no sentido de promover uma relação dialógica em sala de aula e, com isso, viabilizar a aprendizagem significativa para o aluno, é defendida por Assis e Teixeira (2005), que, embasadas em diversos autores, concluem que uma prática pedagógica que utilize textos paradidáticos em aulas de Física, pode mediar: a compreensão dos conceitos trabalhados de modo mais contextualizado, a articulação de diversos conceitos científicos, a articulação dos conteúdos com a realidade do aluno, a formação do aluno enquanto indivíduo crítico, reflexivo e criativo, e a capacidade de ler e interpretar textos.

A utilização de textos paradidáticos pode facilitar a produção escrita, a qual, segundo Vettori e Imhoff (2005), quando bem encaminhada e orientada pelo professor, pode conduzir os sujeitos a reflexões sensivelmente profundas e significativas. Para Rosa e Steffani (2005), a escrita e a leitura precisam ser hábitos estimulados em todas as áreas do saber, inclusive na Física. As autoras comentam ainda que ler e criticar o trabalho alheio é uma forma de ter condições de melhorar o próprio trabalho. Receber críticas é um exercício que a disciplina de Física também pode oferecer, ainda mais porque a crítica dos pares é um fator que participa fortemente na construção da ciência. Giroux (1997) afirma que o que a escola tecnocrática falha em perceber é que escrever é um processo, um modo singular de aprendizagem que corresponde a estratégias de aprendizagem poderosas, que examinam o relacionamento entre o leitor, o assunto e o escritor. $\mathrm{O}$ autor prossegue comentando que a noção de escrita tanto como processo interdisciplinar quanto epistemologia, capaz de ensinar estudantes a pensarem crítica e racionalmente sobre um assunto, não pode ser ignorada; e que, epistemologicamente, o escrever deve ser visto mais como um processo dialético do que como uma habilidade instrumental.

Assolini (2011) ressalta que, em oposição à compreensão de leitura como simples e ingênuo gesto de decodificação - leitura essa que permanece centrada no texto, tratado como portador de significação única a ser desvendado e apreendido por um crédulo leitor -, o enfoque discursivo concebe leitura como construção e produção de sentidos, porém, nem texto, nem autor, nem leitor, sozinhos, são responsáveis pelos sentidos de um texto.

Várias pesquisas (ASSOLINI, 2011; CASSIANI, VON LINSINGEN; GIRALDI, 2011; DRESCH; LEBEDEFF; DICKEL, 2011; LIMA; CARVALHO, 2002) mostram a importância da leitura, no período de infância em casa ou na escola, na formação dos indivíduos, especialmente no que diz respeito à herança cultural que este momento proporciona aos indivíduos na fase adulta, em sua atuação profissional enquanto docentes e na base que utilizam nos momentos de formação, quer seja em nível de Educação de Jovens e Adultos ou em nível de graduação. Esta herança cultural que os alunos trazem da sua vivência dentro e fora da escola é aplicada na forma que estes utilizam para explicar os novos conceitos e conteúdos aprendidos durante a educação formal, na escola e/ou na universidade. Por isto, a utilização de textos diversos na escola e na academia deve proporcionar a dialogicidade e a interação.

Segundo Assis e Teixeira (2005), a construção de um espaço dialógico em sala de aula requer uma mudança de postura do professor superando o discurso autoritário, normalmente utilizado em aulas tradicionais. Para tal, é fundamental que haja espaço para que os estudantes 
exponham as suas ideias, formulem perguntas e trabalhem diferentes pontos de vista. Assim, o professor deve atuar como coordenador, organizando atividades de aprendizagem apoiadas em situações-problema criadas por ele e que serão resolvidas pelos alunos, de forma a propiciar aos alunos um atuar com o saber (PENTEADO, 2000 apud ASSIS; TEIXEIRA, 2005, p. 2).

Freire (2006) destaca que a expressividade é uma necessidade do ser humano, tem de ser estimulada em qualquer nível de educação, pois o domínio da linguagem oral ou escrita é considerado uma das dimensões do processo de expressividade; contudo, é a percepção do aluno sobre a intimidade existente entre linguagem, pensamento e realidade que dá sentido à aprendizagem da linguagem, cujas transformações exigem novas formas de compreensão e de expressão. Silva e Germano (2010) destacam que a utilização da interação dialógica nas aulas de Física conduziu a atividades que induziram os alunos a se expressarem, tanto oralmente quanto na forma escrita; e que os alunos se sentiram extremamente à vontade, tomando iniciativa para participar, propor ideias e considerá-las como hipóteses, ou seja, questionando as ideias propostas, fazendo uso da contrapalavra e discutindo, inclusive, a existência de contradições nas mesmas.

No seu trabalho, Assolini (2011) afirma que é desejável que os futuros pedagogos ${ }^{4}$ possam ocupar o lugar de um sujeito-intérprete (literato), o que lhes poderia assegurar o permanente exercício da crítica e da autocrítica, condição fundamental para o magistério, pois, segundo a autora supracitada, a docência não requer apenas o domínio de conteúdos específicos nas diversas áreas do saber e do ensino, mas, também, conhecimentos didático-pedagógicos, além da compreensão dos aspectos políticos que sustentam a práxis pedagógica do profissional da educação.

Cassiani, Von Linsingen e Giraldi (2011) evidenciam as concepções de leitura como influência importante na busca de formação e atuação profissional que considere o sujeito como leitor de mundo e produtor de sentidos. Para estas autoras, abordar questões oriundas dos estudos de Ciência, Tecnologia e Sociedade (CTS) a partir dessa perspectiva torna-se um caminho muito adequado, na medida em que contribui para que outras leituras sejam realizadas e debatidas como algumas das possíveis, e não as únicas viáveis, abrindo espaço para que a Ciência e a Tecnologia sejam percebidas como construções culturais, localizadas histórica e socialmente.

As autoras continuam afirmando que o processo formativo universitário não deve se limitar ao aprimoramento contínuo e exclusivo de conhecimentos tecnocientíficos descontextualizados, mas tornar possível percorrer outros caminhos, perceber outros cenários e os mesmos cenários com outros olhares, os quais, segundo as autoras, são bastante adequados para favorecer uma abordagem mais polissêmica sobre linguagem e relações CTS. (CASSIANI; VON LINSINGEN; GIRALDI, 2011).

O uso de um texto paradidático, segundo Assis e Teixeira (2005), dentro de uma abordagem dialógica, mostra-se um bom exemplo de uma atividade não linear, uma vez que, a partir de uma determinada discussão inicial acerca de um tema abordado no texto, suscitaramse outros temas inusitados. As autoras supracitadas evidenciaram que o uso do texto paradidático, com a mediação do professor, oportunizou que os alunos explicitassem as suas ideias a

\footnotetext{
${ }^{4}$ Podemos estender isto aos demais licenciandos.
} 
qualquer momento, denotando a sua não-linearidade, bem como viabilizou a articulação entre os aspectos científicos, tecnológicos, sociais, ambientais e políticos, de maneira contextualizada e reflexiva.

Dalri et al. (2005), em atividade de leitura e produção de texto em turmas de Física do Ensino Médio, destacaram que, dependendo do tipo de questão elaborada, é possível perceber o maior ou menor distanciamento das produções escritas dos alunos, em relação ao próprio texto utilizado como suporte inicial. Para os autores, quanto mais específicas eram as questões em relação a um assunto ou conceito apresentado no texto, menos repetição formal ou histórica parecia ocorrer, já que a resposta a tal tipo de questão não favorecia um posicionamento pessoal nem a exposição das ideias construídas ou em construção durante o processo de leitura. Questões que dão uma abertura maior para o aluno se expressar de forma livre e pessoal, possivelmente permitam ou incentivem ao abandono da repetição empírica, na direção da repetição formal ou histórica. Caso isto não ocorra, poderá ocorrer a valorização da busca de informações específicas no texto, o que pode estimular uma simulação de leitura ou uma leitura influenciada pelas expectativas dos alunos em relação ao professor, a si mesmo e à existência de um sentido único do texto, e pelas situações de controle e cobrança (como provas, notas etc.).

Lima e Carvalho (2002), ao analisarem a utilização de um texto literário em aulas de iniciação à Física com crianças, ressaltam que novos problemas surgem a partir da discussão do texto; e que a reflexão proveniente deste momento permitiu que os alunos elaborassem teoricamente situações para explicar o problema, e que, com a evolução da discussão, inclusive o vocabulário empregado foi sendo alterado, chegando à utilização de termos normalmente usados em aulas de Física, sendo, pois, esta mais uma opção para as aulas de iniciação à Física.

Maia (2011) afirma que uma boa metodologia pode reduzir muito a resistência dos alunos em aceitarem ideias difíceis de assimilar, e comenta que, hoje, há sites ou blogs na Internet onde internautas (geralmente, jovens ainda) expressam o seu desagrado e rejeição a disciplinas como Física e Matemática, formando comunidades como: "detesto Física" ou "odeio matemática". Para este autor, faltou, aos professores desses jovens, uma boa metodologia, uma metodologia que mostrasse a eles que até aquilo que é muito difícil pode se tornar mais aceitável.

Maia (2011) utilizou, em turmas de Ensino Médio, além de aulas expositivas, vídeos e um texto paradidático sobre Física das partículas. O autor, ao comentar sobre a utilização do texto paradidático, explicita que este texto proporcionou ganhos na aprendizagem, tornou o conteúdo abordado mais significativo aos alunos, permitiu que ideias e conceitos básicos sobre o conteúdo abordado pudessem ser assimilados de uma forma mais atrativa e estimulante, e que poderia ter ainda maior potencial de aproveitamento caso fosse complementada com vídeos instrutivos específicos dos conteúdos e com programas de edição gráfica de grande poder apelativo.

\section{Metodologia}

Tendo em vista que a LDB (BRASIL, 1996), os PCN (BRASIL, 2000) e os PCN+ (BRASIL, 2002) sugerem que os alunos leiam textos para a compreensão dos fenômenos cien- 
tíficos e o que os autores acima afirmaram ao defenderem a leitura e a escrita na formação do professor e do aluno, então, nos questionamos sobre como fazer o professor utilizar textos diversos, se ele, durante o seu período na escola e na academia, não foi exposto a esta atividade.

Para modificar isto, realizamos três atividades: a primeira consistiu na leitura e discussão de quatro textos paradidáticos que tratam de fenômenos da Física abordados em situações do cotidiano; a segunda etapa consistiu na complementação de um texto já iniciado, o qual deveria ser concluído pelos alunos em trios, explicitando conceitos físicos durante o seu desenvolvimento; a terceira atividade foi a de elaboração de textos integralmente escritos pelos próprios alunos, que, da mesma forma que nas demais etapas, deveriam ter, no seu conteúdo, conceitos da Física.

Neste artigo abordaremos, especificamente, a primeira e a segunda etapas, visto que o material produzido pelos alunos na terceira etapa foi muito rico e carece de artigo específico para tratar acerca dele. Os textos utilizados na primeira etapa foram escritos pelo autor deste artigo, visto que o mesmo não encontrou textos paradidáticos ou de divulgação mais curtos, apenas livros. Os textos curtos localizados tratavam apenas da história da Física, em especial, sobre a vida de grandes cientistas.

Os textos utilizados em sala de aula na primeira etapa tratavam de assuntos de Física observados em situações do dia a dia, expostos de forma literária. O primeiro foi "A história do calendário" , que trata da construção do calendário, baseado no movimento dos corpos celestes; o segundo foi "Boia ou afunda", que aborda questões sobre a densidade e empuxo; o terceiro, "Ciclo da água", que explica como ocorre a formação das nuvens e as mudanças de estados físicos; e o quarto, "Desnorteados", que fala sobre o magnetismo, em especial abordando o funcionamento da bússola e os polos magnéticos terrestres. Esta atividade ocorreu em duas aulas de Metodologia do Ensino de Física ${ }^{6}$, do curso de licenciatura em Física da Universidade Federal do Piauí (UFPI), na qual se encontravam matriculados 23 alunos. Os alunos foram divididos em quatro grupos, e cada um dos grupos recebeu um dos textos citados, de forma que os quatro grupos estavam de posse de textos diferentes entre si. O grupo 1 ficou com o texto 1, "A história do calendário"; o grupo 2 com o texto 2, "Boia ou afunda"; o grupo 3 com o texto 3, "Ciclo da água", e o grupo 4 com o texto 4, "Desnorteados".

Foi solicitado que cada grupo lesse o seu texto e, posteriormente, discutisse as seguintes questões: (1) Existe(m) algum(ns) conceito (ou conceitos) de Física neste texto? Se sim, qual (is)?; (2) Se a sua resposta foi sim, este(s) conceito(s) foi (ram) bem trabalhado(s)? Justifique; (3) É possível utilizar textos como este em sala de aula? Em que momento(s) ou situação (ões)?; (4) Poderia ser feito algo para melhorá-lo? Apresente alguma(s) sugestão (ões). Após as discussões, os alunos deveriam registrar, por escrito, as suas respostas.

\footnotetext{
${ }^{5}$ Os textos "A história do calendário", "A lenda da cesta infinita", "Boia ou afunda", Ciclo da água" e "Desnorteados" foram escritos pelo autor deste artigo, e não foram publicados, daí a ausência de referências ao final do trabalho.

${ }^{6}$ Nesta disciplina, consta na ementa, entre outras coisas, técnicas em ensino de Física e materiais didáticos e paradidáticos de Física, o que justifica ainda mais a elaboração destas atividades.
} 
Em seguida, cada um dos textos foi lido para toda a turma, e os integrantes da equipe que analisou o texto lido relatavam as suas respostas, e era aberta a discussão para os demais grupos, se concordavam ou não com as colocações feitas. O pesquisador também registrou, em um diário de campo, as observações feitas durante a execução da atividade.

$\mathrm{Na}$ segunda etapa, os alunos foram divididos em trios, formando ao todo seis trios ${ }^{7}$. Esta atividade teve a duração de quatro aulas. Para a nossa explanação neste artigo, nomearemos os trios de "A" a "F". Esta etapa consistiu na leitura de um texto incompleto, pelo professor da turma, o qual cada um dos grupos teria de completá-lo, utilizando conceitos de Física para isto. O texto lido foi "A lenda da cesta infinita", também redigido pelo professor da disciplina, e apresentava-se assim aos alunos:

Há muito tempo atrás estava ocorrendo uma grande fome na terra de Ibimirim. Eugênio Valente, um garoto simples, mas com grandes conhecimentos em Física, querendo ajudar a resolver o problema do seu povo, ficou sabendo da lenda da cesta infinita e resolveu ir procurá-la. A cesta infinita, segundo a lenda, era uma cesta repleta de alimentos, a qual, se um alimento for retirado, surge outro idêntico no seu lugar, sendo, pois, uma fonte inesgotável de comida. Esta cesta resolveria o problema de fome de Ibimirim.

Eugênio, ao ouvir falar da cesta, procurou mais informações para saber se era verdade. Falou com todos os moradores antigos da cidade e estes lhe confirmaram a história. Astrogildo, o ancião mais velho da cidade, lhe disse:

- Dizem que na Caverna da Escuridão existe um mapa que conduz à cesta, só que ninguém consegue encontrar esta caverna e, os que a encontram, após entrarem nela não conseguem mais encontrar a sua saída. Ao ouvir o ancião, Eugênio ficou temeroso, mas decidiu ir em busca desta caverna, só que, para isto, ele precisava construir alguns equipamentos que lhe seriam bastante úteis: uma bússola para guiar os seus passos, uma lanterna que pudesse iluminar por um bom tempo (poderia ser a sua única oportunidade de entrar e sair da caverna!), um recipiente térmico (Eugênio gostava muito de água gelada!) e um transporte para ele conseguir andar muito e mais rapidamente que a pé. Ele não sabia o que o esperava, então era necessário que ele fizesse uma pequena mala para enfrentar possíveis adversidades de frio ou calor, sol ou chuva, etc. [Continuar...]

Após lerem este início, os trios se reuniram e começaram a pensar e redigir a estória, com a supervisão e acompanhamento do professor. Os resultados destas duas atividades estão descritos na seção seguinte.

\footnotetext{
${ }^{7}$ A turma conta com um total de 23 alunos matriculados. Destes, 21 frequentam regularmente as aulas, mas, nesta aula, faltaram três destes, o que nos deu um total de 18 alunos na aula.
} 


\section{Resultados e discussões}

\section{Primeira etapa}

Após a leitura dos textos, foi realizada uma discussão sobre os mesmos, investigando se os licenciandos encontravam conceitos de Física inseridos nos textos, bem como se foram bem trabalhados e se era possível utilizá-los em sala de aula.

Em relação à primeira questão, os licenciandos, unanimemente, concordaram que haviam conceitos de Física envolvidos, e os resultados desta questão encontram-se redigidos no Quadro 1.

Quadro 1. Existe(m) algum(ns) conceito (ou conceitos) de física neste texto? Se sim, qual (is)?

\begin{tabular}{|c|l|l|l|l|}
\hline \multicolumn{1}{|c|}{ Texto } & A história do calendário & Boia ou afunda & \multicolumn{1}{c|}{ Ciclo da água } & Desnorteados \\
\hline $\begin{array}{c}\text { Conceitos } \\
\text { envolvidos }\end{array}$ & $\begin{array}{l}\text { Movimentos planetários } \\
\text { Medida de tempo } \\
\text { Sistema heliocêntrico }\end{array}$ & Densidade & $\begin{array}{l}\text { Calor } \\
\text { Variação de temperatura } \\
\text { Mudança de fase } \\
\text { Radiação }\end{array}$ & Magnetismo \\
\hline
\end{tabular}

Fonte: Elaborado pelo autor.

Como podemos perceber no quadro acima, os quatro grupos concordaram que, nos textos analisados, haviam, inseridos em seu conteúdo, conceitos de Física. Nos textos "A história do calendário" e "Ciclo da água" foram listados alguns conceitos pelos alunos, e estes conceitos encontram-se relacionados entre si. Nos textos "Boia ou afunda" e "Desnorteados", foi listado um único conceito de Física em cada.

Este fato nos leva a analisar a segunda questão: "Se a sua resposta foi sim, este(s) conceito(s) foi(ram) bem trabalhado(s)? Justifique". Como todos os grupos listaram conteúdos de Física presentes nos textos, eles afirmaram que estes conceitos foram bem trabalhados, dependendo do nível em que o texto fosse utilizado, pois, segundo os próprios alunos, havia textos que estavam redigidos de forma mais básica, introdutória, como "O ciclo da água" e "A história do calendário", que seriam voltados para alunos do Ensino Fundamental; e os textos "Desnorteados" e "Boia ou afunda", por apresentarem maior profundidade teórica, poderiam ser utilizados no Ensino Médio. Talvez, por este mesmo motivo, nos textos voltados para o Ensino Médio, os alunos detectaram um único conteúdo de Física, enquanto, nos demais, que eram "introdutórios", os alunos listaram mais de um conteúdo de Física abordado.

A resposta a esta questão do grupo 2, sobre o texto "Boia ou afunda", ilustra bem a visão dos alunos sobre a forma de se trabalharem os conceitos nos textos: "Sim [o conceito foi bem trabalhado]. Pois foi bem exemplificado e bem direto quando há a abordagem em relação da massa de um corpo à massa do mesmo volume de outro corpo". O grupo 1, que analisou o texto "A história do calendário", respondeu o seguinte: "Os conceitos foram trabalhados de forma superficial. A forma de como foi passada [sic], tem o objetivo de despertar interesse do leitor". 
Os trechos acima explicitam que os alunos acharam interessante a utilização dos textos paradidáticos, e que a utilização dos mesmos tem objetivos distintos das aulas tradicionais de Física, que contam, normalmente, com fórmulas e descontextualizadas da realidade do aluno, pois, como especificou o grupo 4, "usa a criatividade para instigar o interesse sobre o magnetismo" ou sobre qualquer outro conceito que venha a ser trabalhado nos textos.

Em relação à terceira questão, "É possível utilizar textos como este em sala de aula? Em que momento(s) ou situação(ões)?”, os licenciandos em Física também concordaram que era possível e seria interessante que fossem trabalhados em sala de aula, pois instigaria os alunos a investigarem os fenômenos físicos no seu cotidiano e os faria compreender que a Física existe para explicar fenômenos que ocorrem ao nosso redor, no nosso dia a dia. O grupo 3 comentou que poderiam ser utilizados quando há necessidade de contextualização do conteúdo abordado em sala e, também, para reter a atenção do aluno para o assunto.

O grupo 4 também afirmou que estes textos poderiam ser utilizados em momentos que a maioria não demonstra interesse pelo assunto. $\mathrm{O}$ grupo 1 respondeu que poderiam ser utilizados antes do conteúdo específico, como um motivador ou elemento introdutor do assunto a ser abordado; e, por fim, o grupo 3 comentou que os textos poderiam ser utilizados "no início como motivação e no final como exemplo da utilidade prática dos conceitos".

Com base nas respostas, fica evidente que os textos poderiam ser utilizados em sala de aula em conjunto com a aula tradicional; e que, com isto, agregaríamos um maior interesse pela Física por parte dos alunos, pois os mesmos passariam a vê-la mais facilmente como presente no nosso cotidiano.

E, em relação à última questão, "Poderia ser feito algo para melhorá-lo? Apresente alguma(s) sugestão(ões)", o grupo 1 respondeu que alguns conceitos presentes no texto não foram aceitos tão rapidamente, e enfatizaram a importância de desenvolver melhor a contextualização histórica presente no mesmo. Isto também se deve ao fato de que os textos foram curtos, com apenas duas laudas cada um, não sendo, portanto, possível um grande aprofundamento tanto em termos teóricos e conceituais quanto em termos históricos.

Já os alunos do grupo 4 responderam que nada poderia ser feito para melhorá-lo e nada sugeriram; e os dos grupos 2 e 3 destacaram que, como tratavam-se de textos sem ilustrações, caso fossem ilustrados, a sua compreensão se daria de forma mais completa, seriam mais bem compreendidos, tal como também fora percebido por Maia (2011) em seu trabalho.

\section{Segunda etapa}

Após terem contato com textos que eles próprios julgaram ter conceitos de Física e serem aplicáveis em sala de aula, os licenciandos investigados leram o início do texto "A lenda da cesta infinita" e, em trios, discutiram como completá-lo, usando, neste texto, necessariamente, algum(ns) conceito(s) de Física. Como alguns grupos apresentavam muitas dificuldades, o professor, durante o acompanhamento às equipes, deu algumas dicas para que os alunos desenvolvessem os textos. As dicas foram: e se tivesse uma pedra grande na entrada da caverna?; E se Eugênio Valente precisasse atravessar um rio? E se ele quisesse comer um fruto que está no alto de uma árvore?

Com estas sugestões, os grupos que estavam com maiores dificuldades puderam desenvolver a estória, completando-a. Foi verificado, ao término da atividade que, embora o 
início tenha sido o mesmo para todos os grupos, todos os textos apresentaram finais bastante diferentes, bem como a escrita do mesmo também variou muito entre as equipes. Os conceitos físicos abordados em cada equipe foram: A - Alavanca; B - Eletricidade, magnetismo; C - Magnetismo, alavanca, eletricidade (circuitos elétricos), densidade; D - densidade, Física térmica (isolantes térmicos), astronomia, pressão, eletricidade (poder das pontas); E - alavanca, atrito/calor, densidade, deslocamento, lançamento; F - atrito/calor.

Podemos perceber que os conceitos abordados foram abundantes, porém, na sua maioria, abordados de forma superficial, como, por exemplo:

Para a construção da bússola foi utilizado um copo de vidro ou de plástico, uma agulha de costura, um imã, um pedaço de papel tipo jornal, para a lanterna utilizou-se quatro limões, fios de cobre e zinco, garras de jacaré térmica [sic] [seria a garrafa] foi utilizado um porango [sic] para armazenamento do líquidos [sic]. [Grupo B]

Percebemos que, quem já apresentava um conhecimento de Física, compreendeu o que fora escrito no texto, porém, como a proposta era de redigir textos para alunos de Ensino Médio, a compreensão de como ocorreu a construção da bússola e/ou da lanterna, citadas acima, fica bem difícil, especialmente se os alunos não têm uma boa base em Física ou não realizam experimentos. Alguns grupos (C, D e E) fizeram trabalhos de melhor qualidade e aprofundamento na Física, e inseriram, ao longo do texto, diversos conceitos. A superficialidade conceitual ocorreu em todos os textos, demonstrando a dificuldade que os licenciandos têm de explicar os conceitos e torná-los compreensíveis em sua plenitude aos alunos do Ensino Médio.

Os erros ou incoerências conceituais estiveram presentes na metade dos textos (Grupos A, C e F). Como exemplo, na área da Física, podemos citar:

Na entrada da caverna ele perceben que estava muito escuro, pegon duas pilhas e conectou em série com a lâmpada (pois a Lâmpada funcionava com três volts, e as pilhas que ele tinha era de apenas 1,5 volts cada, se estivesse [sic] colocado em paralelo a mesma não acenderia pois só iria fornecer 1,5 volts para a lâmpada). Com isto iluminou o caminho e seguio [sic] em frente. [Grupo C]

Embora os três autores deste texto sejam alunos bolsistas do Programa Institucional de Iniciação à Docência (PIBID) e, constantemente, realizem experimentos, eles erraram ao afirmar que a lâmpada de 3,0 volts não acenderia com 1,5 volts. Ela acenderia, porém com uma intensidade luminosa mais baixa. Ocorreram erros conceituais em outras áreas, como na Geologia e Biologia, conforme nos mostram os trechos do Grupo A, abaixo:

Ao se aproximar da caverna Eugênio [...] viu que havia árvore e pedras que o impediam de entrar, mas como era conhecedor da Geologia das rochas viu que as mesmas eram de um material que se desintegravam facilmente após o contato com a água [...] passou a transportar pequenas quantidades de água fazendo com que as rochas fossem se deteriorando, perdendo a sua rigidez e com a perda de energia gerada pela reação da explosão da rocha era liberado [sic] muita energia térmica que passava a queimar o caule da árvore que também o impediam [sic]. 
[...] percebeu que na caverna existia não só rocha mas também um grande lago construido pelos pingos que caem do alto [...] entre frechas [sic] das pedras e água abundante havia um ser vivo, era um pequeno animal aquático que emitia luz capaz. de iluminar por um pequeno espaço de tempo. Foi então que Eugênio pensou que se o peixe estava ali teria ele que ter contato com o Sol.

O primeiro trecho fica difícil de ser compreendido, até mesmo se pensarmos no sódio, que reage com a água e libera grande quantidade de calor, pois este também reage com o oxigênio do ar. Sobre o segundo trecho, o fato de haver um ser vivo na água não implica que ele tenha contato com o Sol, pois sabemos que existem milhares de seres vivos que vivem sem nunca ter contato com a luz, desenvolvendo, para a sua sobrevivência, órgãos táteis sensíveis e sentidos (exceto a visão) bem apurados. Enfatizamos que todos os textos com as devidas correções foram entregues e comentados com os alunos, possibilitando que estes, na terceira etapa (escrita de um texto completo), minimizassem este tipo de ocorrência, o que, de fato, aconteceu.

Os conceitos físicos mais abordados foram a alavanca e a eletricidade, com três grupos citando-os, A, C e E e C, D e E, respectivamente. Estes conceitos também foram vistos de forma superficial, que não apresenta para o leitor, especialmente se este for leigo em Física, como o conceito abordado acontece. Como exemplo, podemos citar o trecho do Grupo C que trata sobre a alavanca:

[...] na entrada [da caverna] havia uma pedra bem grande [...] Ele [Eugênio] teve uma ideia, pegou um longo pedaço de madeira fazendo com isso uma lavanca [sic] conseguindo tirar a pedra da entrada da caverna pois à lavanca [sic] maximizou a força aplicada sobre a pedra. [Grupo C, grifos do autor]

\section{Conclusões}

Com base nas observações realizadas e nas respostas e colocações dos alunos investigados, verificamos que a utilização de textos paradidáticos, em especial de textos literários sobre Física, é algo interessante de ser realizado em sala de aula e pode proporcionar o interesse dos alunos pela temática abordada, bem como pode aproximar mais a Física do seu cotidiano. Os momentos de leitura e discussão sobre os textos paradidáticos ocorridos nas aulas serviram para mostrar, para os alunos, que se poderia falar de Física sem utilizarmos, necessariamente, fórmulas e outras estratégias que se encontram distantes de sua própria realidade. A utilização dos textos poderia ser uma forma de fazer os alunos compreenderem melhor o que as fórmulas trabalham, e o texto poderia ser uma forma de introduzi-las ou de aplicá-las.

Em relação à segunda etapa, os alunos apresentaram grande dificuldade para a escrita, inclusive com pouco domínio da língua portuguesa formal. Na maioria dos casos, os conceitos de Física foram abordados de maneira superficial e, às vezes, até vistos de forma errada. Embora houvesse uma preocupação com a contextualização dos conteúdos com a realidade dos alunos, esta contextualização foi extremamente vaga, quando houve! Devemos levar em consideração ser a primeira vez que estes alunos realizaram uma atividade desta maneira. Acreditamos que, ao 
produzirem outros textos desta natureza, a contextualização ocorrerá de forma mais concreta e consistente.

Segundo Lima (2006), o mundo atual requer um novo tipo de profissional, cujos saberes sejam polivalentes e, sobretudo, amplos e sólidos, para corresponder às peculiaridades e ao caráter multifacetado da prática pedagógica. Para que isto ocorra, é necessário considerarmos o ensino como um processo que facilita a transformação permanente do pensamento, das atitudes e dos comportamentos dos (as) alunos (as), provocando a comparação de suas aquisições mais ou menos espontâneas em sua vida cotidiana com as proposições das disciplinas científicas, artísticas e especulativas, e também estimulando a sua experimentação na realidade (PÉREZ GÓMEZ, 1998). Isto ocorrerá quando deixarmos de observar a sala de aula como um modelo de processo-produto ou como um modelo mediacional centrado no aluno ou no professor, e sim, quando observarmos a sala de aula por meio de uma perspectiva ecológica, assumindo a recíproca influência nas relações de classe entre professores (as) e alunos (as), enfatizando o indivíduo como processador ativo de informação e dando a devida importância à criação e troca de significados subjacentes aos comportamentos.

A formação pela experiência, defendida por Houssaye (2004), proporciona que o futuro professor repense a sua forma de lecionar. Por isto, esta proposta de utilizar textos paradidáticos em momentos de formação de futuros licenciandos em Física pode ser um dos mecanismos para melhorarmos o ensino desta disciplina, bem como diminuirmos, também, o alto índice de rejeição dos alunos por esta disciplina.

Sabemos também que, dificilmente, os professores atuam de forma diferente da qual foram formados, pois os saberes oriundos da formação anterior (escola) influenciam muito na forma de atuação do professor (TARDIF, 2000, 2004). Então, ao expormos os licenciandos a atividades diferenciadas, os mesmos terão ampliadas as suas possibilidades futuras de atuação docente, bem como também favorece o aprendizado dos seus futuros alunos, os quais não pensam de maneira uniforme; além do que os PCN (BRASIL, 2000, 2002) sugerem o uso de diferentes metodologias no ensino de Física e das demais disciplinas também.

Enfatizamos que a utilização de textos paradidáticos na formação dos futuros professores de Física não irá suprir todas as dificuldades dos seus futuros alunos para a compreensão e o interesse pela Física, mas mostra-se como um elemento motivador e que, certamente, ampliará as metodologias possíveis de serem aplicadas na escola básica. Não existe uma metodologia única que resolva o problema da dificuldade de compreensão dos conceitos de Física pelos alunos e se mostre eficaz para que seja utilizada isoladamente das demais metodologias, e sim, a utilização de várias metodologias articuladas entre si, tais como: aulas expositivas, debates, simulações computacionais, experimentos, entre outras - às quais a utilização de textos paradidáticos vem a ser acrescida e mostra-se uma ferramenta importante, devido ao seu baixo custo, fácil aplicação e a possibilidade de adequação à realidade dos alunos que a utilizarão. 
A leitura e a escrita de textos paradidáticos ...

\section{Referências}

ALMEIDA, M. J. P. M.; SORPRESO, T. P. Dispositivo analítico para compreensão da leitura de diferentes tipos textuais: exemplos referentes à Física. Pro-Posições, Campinas, v. 22, n. 1, p. 83-95, jan./abr. 2011. Disponível em: <http://www.scielo.br/pdf/pp/v22n1/08. pdf>. Acesso em: 02 maio 2012.

ANDRADE, C. R.; MAIA JR., M. S. Ensino da Física e o cotidiano: a percepção do aluno de licenciatura em Física da Universidade Federal de Sergipe. Scientia Plena, Aracaju, v. 4, n. 4, p. 044401-1- 044401-8, abr. 2008. Disponível em: <http://www.scientiaplena.org.br/ ojs/index.php/sp/article/viewFile/610/268>. Acesso em: 17 maio 2012.

ASSIS, A.; TEIXEIRA, O. P. B. Análise de um episódio de ensino envolvendo o uso de um texto paradidático em aulas de Física em uma sala de educação de jovens e adultos. In: ENCONTRO NACIONAL DE PESQUISA EM EDUCAÇÃO EM CIÊNCIAS, 5., 2005, Bauru. Atas... Disponível em: < http://www.nutes.ufrj.br/abrapec/venpec/conteudo/ artigos/3/pdf/p45.pdf>. Acesso em: 02 maio 2012.

ASSOLINI, F. E. P. Leitura e formação inicial de professores: sentidos, memória e história a partir da perspectiva discursiva. Pro-Posições, Campinas, v. 22, n. 1, p. 33-43, jan./abr. 2011. Disponível em: <http://www.scielo.br/pdf/pp/v22n1/04.pdf>. Acesso em: 02 maio 2012.

BEZERRA, D. P. et al. A evolução do ensino da Física: perspectiva docente. Scientia Plena, Aracaju, v. 5, n. 9, p. 094401-1 - 094401-8, set. 2009. Disponível em: <http:// www.scientiaplena.org.br/ojs/index.php/sp/article/viewFile/672/342>. Acesso em: 17 maio 2012.

BRASIL. Lei no 9.394, de 20 de dezembro de 1996. Estabelece as diretrizes e bases da educação nacional. Diário Oficial da União, Brasília, 23 dez. 1996. p. 27833. Disponível em: <https://www.planalto.gov.br/ccivil_03/Leis/L9394.htm>. Acesso em: 05 ago. 2008.

. Ministério da Educação. Matriz de referência para o Enem 2009. Brasília, 2009.

Disponível em: <http://portal.mec.gov.br/index.php?option=com_docman\&task=doc_ download\&gid=841\&Itemid $>$. Acesso em: 27 fev. 2012.

Parâmetros curriculares nacionais: ensino médio: bases legais. Brasilia, 2000.

Disponível em: < http://portal.mec.gov.br/seb/arquivos/pdf/blegais.pdf > . Acesso em: 27 abr. 2015.

\section{PCN + ensino médio: orientações educacionais complementares}

aos parâmetros curriculares nacionais. Ciências da natureza, matemática e suas tecnologias. Brasília, [2002]. Disponível em: <http://portal.mec.gov.br/seb/arquivos/pdf/ CienciasNatureza.pdf $>$. Acesso em: 27 abr. 2015.

CASSIANI, S.; VON LINSINGEN, I.; GIRALDI, P. M. Histórias de leituras: produzindo sentidos sobre ciência e tecnologia. Pro-Posições, Campinas, v. 22, n. 1, p. 59-70, jan./abr. 2011. Disponível em: <http://www.scielo.br/pdf/pp/v22n1/06.pdf>. Acesso em: 02 maio 2012. 
CASTELLÓ, M.; BAÑALES FAZ, G.; VEGA LÓPEZ, N. A. Leer múltiples documentos para escribir textos académicos en la universidad: o cómo aprender a leer y escribir en el lenguaje de las disciplinas. Pro-Posições, Campinas, v. 22, n. 1, p. 97-114, jan./abr. 2011. Disponível em: < http://dx.doi.org/10.1590/S0103-73072011000100009>. Acesso em: 17 maio 2012.

CAVALCANTE, D. C. M. et al. A representação social construída por licenciandos acerca do curso de Física. Scientia Plena, Aracaju, v. 5, n. 8, p. 82702-1 - 82702-5, ago. 2009. Disponível em: <http://www.scientiaplena.org.br/ojs/index.php/sp/article/ view/642/304>. Acesso em: 17 maio 2012.

DALRI, J. et al. Reflexões sobre leitura e produção escrita em aulas de Física: uma experiência no ensino médio. In: ENCONTRO NACIONAL DE PESQUISA EM EDUCAÇÃO EM CIÊNCIAS, 5., Bauru, 2005. Atas... Disponível em: < http://www.nutes. ufrj.br/abrapec/venpec/conteudo/artigos/1/pdf/p866.pdf>. Acesso em: 13 maio 2012.

DRESCH, M.; LEBEDEFF, T. B.; DICKEL, A. Memórias de leitura, lugar de leitor e conhecimento na formação inicial de docentes. Pro-Posições, Campinas, v. 22, n. 1, p. 45-58, jan./abr. 2011. Disponível em: <http://www.scielo.br/pdf/pp/v22n1/05.pdf>. Acesso em: 02 maio 2012.

FREIRE, A. M. A. Paulo Freire: uma história de vida. Indaiatuba: Villa das Letras, 2006. Pedagogia da autonomia: saberes necessários à prática educativa. 29. ed. Rio de Janeiro: Paz e Terra, 2004.

GIROUX, H. A. Os professores como intelectuais: rumo a uma pedagogia crítica da aprendizagem. Porto Alegre: Artes Médicas, 1997.

HOUSSAYE, J. Pedagogia: justiça para uma causa perdida. In: HOUSSAYE, J. et al. Manifesto a favor dos pedagogos. Porto Alegre: Artmed, 2004. p. 9-45.

LIMA, M. C. B.; CARVALHO, A. M. P. “Exercícios de raciocínio” em três linguagens: ensino de Física nas séries iniciais. Ensaio: Pesquisa em Educação em Ciências, Belo Horizonte, v. 4, n. 1, p. 1 -21, 2002. Disponível em: <http://www.portal.fae.ufmg.br/seer/index.php/ ensaio/article/viewFile/48/366>. Acesso em: 02 maio 2012.

LIMA, M. G. S. B. Sujeitos e saberes, movimento de auto-reforma da escola. In: MENDES SOBRINHO, J. A. C.; CARVALHO, M. A. (Org.). Formação de professores e práticas docentes: olhares contemporâneos. Belo Horizonte: Autêntica, 2006. p. 31-39.

MAIA, M. C. Uma abordagem do modelo padrão da Física de partículas acessível a alunos do ensino médio. 2011. 70 f. Dissertação (Mestrado Profissional no Ensino de Ciências e Matemática) - Centro de Ciências, Universidade Federal do Ceará, Fortaleza, 2011. Disponível em: <http://www.repositorio.ufc.br:8080/ri/ bitstream/123456789/1452/1/2011_dis_mcmaia.PDF>. Acesso em: 02 maio 2012. 
MONTEIRO, M. A. A.; TEIXEIRA, O. P. B. O ensino de Física nas séries iniciais do ensino fundamental: um estudo das influências das experiências docentes em sua prática em sala de aula. Investigações em Ensino de Ciências, Porto Alegre, v. 9, n. 1, p. 7-25, mar. 2004. Disponível em: < http://www.if.ufrgs.br/ienci/artigos/Artigo_ID108/v9_n1_a2004.pdf>. Acesso em: 17 maio 2012.

PÉREZ GÓMEZ, A. I. Ensino para a compreensão. In: GIMENO SACRISTÁN, J.; PÉREZ GÓMEZ, A. I. Compreender e transformar o ensino. 4. ed. Porto Alegre: Artmed, 1998. p. 67-97.

REIS, E. M.; LINHARES, M. P. Integrando o espaço virtual de aprendizagem "Eva" à formação de professores: estudo de caso sobre o currículo de Física no ensino médio. Ensaio: Pesquisa em Educação em Ciências, Belo Horizonte, v. 10, n. 2, p. 1-22, 2008. Disponível em: < http://150.164.116.248/seer/index.php/ensaio/article/view/155/225>. Acesso em: 17 maio 2012.

ROSA, K.; STEFFANI, M. H. Produção textual no ensino de Física: o estímulo à escrita através da história com o uso de material paradidático. In: SIMPÓSIO NACIONAL DE ENSINO DE FÍSICA, 16., 2005, Rio de Janeiro. Atas... Disponível em: < http://www.sbf1. sbfisica.org.br/eventos/snef/xvi/cd/resumos/T0036-1.pdf>. Acesso em: 17 maio 2012.

SILVA, R. R.; GERMANO, A. S. M. Focalizando a linguagem oral e escrita no ensino de Física para adultos: um estudo através da temática clima. In: ENCONTRO DE PESQUISA EM ENSINO DE FÍSICA, 12., 2010, Águas de Lindóia. Atas... São Paulo: Sociedade Brasileira de Física, 2010. p. 1-12.

TARDIF, M. Saberes docentes e formação profissional. 4. ed. Petrópolis: Vozes, 2004. . Saberes profissionais dos professores e conhecimentos universitários: elementos para uma epistemologia da prática profissional dos professores e suas consequências em relação à formação para o magistério. Revista Brasileira de Educação, Rio de Janeiro, n. 13, p. 5-24, 2000. Disponível em: < http://anped.org.br/rbe/rbedigital/RBDE13/ RBDE13_05_MAURICE_TARDIF.pdf>. Acesso em: 27 abr. 2015.

TEIXEIRA, P. M. M. A educação científica sob a perspectiva da pedagogia histórico-crítica e do movimento C.T.S. no ensino de ciências. Ciência \& Educação, Bauru, v. 9, n. 2, p. 177-190, 2003. Disponível em: <http://www.scielo.br/pdf/ciedu/v9n2/03.pdf>. Acesso em: 17 maio 2012.

VETTORI, M.; IMHOFF, A. L. Educar pela pesquisa em Física. In: ENCONTRO NACIONAL DE PESQUISA EM EDUCAÇÃO EM CIÊNCIAS, 5., Bauru, 2005. Atas... Disponível em: <http://www.nutes.ufrj.br/abrapec/vienpec/CR2/p743.pdf >. Acesso em: 26 jun. 2012. 